American Journal of Applied Sciences 6 (5): 843-847, 2009

ISSN 1546-9239

(C) 2009 Science Publications

\title{
The Effect of Acute Administration of Artemisia Persia Extracts on Arterial Blood Pressure and Heart Rate in Rats
}

\author{
Farzaneh Esmaeili, Gholamreza Sepehri, Ghollam-Reza Moshtaghi-Kashanian, \\ Mohammad Khaksari, Najme Salari and Ehsan Sepehri \\ Department of Physiology and Pharmacology and Physiology Research Center, \\ School of Medicine, Kerman University of Medical Sciences, Kerman, Iran
}

\begin{abstract}
Problem statement: Artemisia Persia (AP) used for its therapeutic effects in folk medicine whiles some species of Artemisia shown a hypotensive effect. To determine the cardiovascular effect of AP, we tested the pharmacological responses of aqueous and methanolic extracts of AP on blood pressure (BP) and Heart Rate (HR) of normotensive and ephedrine induced hypertensive rats using a tail-cuff computerized registering device. Approach: Hypertension was produced by single dose of ephedrine $\left(40 \mathrm{mg} \mathrm{kg}^{-1} \mathrm{IM}^{-1}\right)$ to raise BP $20-30 \mathrm{mmHg}$. Animals were fed with different concentrations of each extracts $\left(300,400\right.$ and $\left.500 \mathrm{mg} \mathrm{kg}^{-1}\right)$ by gavage method. BP and HR were recorded before and during 40 min following aqueous and methanolic extracts administrations in 5 min intervals. Results: The most effective concentration of both extracts to reduced systolic BP of normotensive rats was 400 $\mathrm{mg} \mathrm{kg}{ }^{-1}$ after 20 min consumption ( $<<0.005$ ), while none of administrated doses affected diastolic BP or HR. The efficacy of extracts was tested in hypertensive rats and the results were compared with the effect of enalapril (30 mg kg${ }^{-1}$ ). Conclusions/Recommendations: Oral consumption of AP extracts after 20 min reduced systolic BP in normotensive and hypertensive rats, while the aqueous extract of $\mathrm{AP}$ reduced the BP of hypertensive rats more effectively than enalapril. Hence precaution should be taken when this herb is consumed as a remedy.
\end{abstract}

Key words: Artemisia persia, blood pressure, heart rate, rat

\section{INTRODUCTION}

Artemisia is a plant found throughout the world including Iran and used for its therapeutic effects in folk medicine. In Iran it is used as a remedy for digestive problem and fungicidal growth. It is reported that Artemisia аппиа and its derivatives are used as a potent new class of antimalarial agents in China ${ }^{[1,2]}$. Different therapeutic effects, such as anthelmintic, digestive remedy and antidiarrhea effects are also were reported ${ }^{[3]}$. There are reports showing that some species of Artemisia has antiinflammatory, antitumor and antiparasitic effects ${ }^{[4,5]}$.

The effects of Artemisia on cardiovascular events shown that Scoparone (a coumarin derivative isolated from the Chinese crude drug Artemisiae capillaries flos) could increase coronary flow and heart rate, but could not affect cardiac output and left ventricular performance in isolated perfuse rats' heart ${ }^{[6,7]}$. Since, they detected an inhibitory effect on the ST wave depression, concluded that scoparone has an antianginal action $^{[6,7]}$. There are also reports showing Artesunate (semi-synthetic derivative of artemisinin extracted from the plant Artemisia annua) could inhibit angiogenesis both in vitro as well and in vivo ${ }^{[2,8,9]}$. Calderone and coworkers $^{[10]}$ also showed the aqueous dried extract of Artemisia verlotorum had a marked, but transient, hypotensive activity in the isolated perfuse rat mesentery, while tigno and colleagues showed extracts from Artemisia vulgaris has no effects on mean arterial blood pressure and heart rate in a model of ischemiareperfusion injury in the rat intestinal mesentery ${ }^{[11]}$. On the contrary, administration of aqueous extract fractions of Artemisia vulgaris was highly effective in reversing the hypertensive action induced by norepinephrine ${ }^{[7]}$ and did not exert any significant effect on heart rate in either the normotensive or hypertensive state ${ }^{[12]}$.

Since there are controversial reports on cardiovascular effects of aqueous or methanolic extracts of Artemisia (different species) in normotensive and

Corresponding Author: Ghollam-Reza Moshtaghi-Kashanian, Department of Biochemistry, Physiology Research Center, School of Medical, Kerman University of Medical Sciences, Kerman, Iran Tel: +98 (341) 2442605, +989133414240 Fax: +98 (341) 2442100 
hypertensive cases, lack of symmetrical investigations on both extracts and widely use of this herb by people in Iran, this study was performed to evaluate the in vivo effect of aqueous and methanolic extracts of Artemisia Persia (AP) grown in Kerman province of Iran on Blood Pressure (BP) and Heart Rate (HR) of normotensive and ephedrine induced hypertensive male rats.

\section{MATERIALS AND METHODS}

Drugs: Ephedrine hydrochloride was purchased from $\mathrm{G}$ Streul and Company (AG. Uznach). Enalapril (Darou Pakhsk Pharmacological Company, Tehran, Iran) an Angiotensin Converting Enzyme Inhibitor (ACEI), was used as a standard antihypertensive agent ${ }^{[3]}$.

Preparation of AP extracts: During spring season, the leaves of Artemisia annue (locally called as Dermaneh) were collected from deserts of Kerman province of Iran. The plant was identified and confirmed by a botanist in the biology department of Shahid-Bahonar University (Kerman, Iran) as Artemisia Persia (AP). To prepare aqueous and methanolic extracts, the leaves were air-dried and powdered. For methanolic extract $100 \mathrm{~g}$ of powder was soaked in $1000 \mathrm{~mL}$ of $80 \%$ methanol (Merck Company, Germany) for $72 \mathrm{~h}$. The extract was shaken, filtered and evaporated in a rotating evaporator under reduced pressure until dryness. Evaporation and solvent removal of methanolic extract gave a semi-solid mass yielded $10 \% \mathrm{~W} / \mathrm{W}$. The extract was kept in clean, dried bottle that was placed in a desiccator. Stock solution of the extract was prepared by dissolving $5 \mathrm{~g}$ of extract in $100 \mathrm{~mL}$ of distilled water to prepare a $50 \mathrm{mg} \mathrm{mL}^{-1}$ concentration. Other concentrations were made from this stock solution by appropriate dilution with distilled water. Water extract of AP was prepared by socking $100 \mathrm{~g}$ of the powdered leaves in $1000 \mathrm{~mL}$ of distilled water for $72 \mathrm{~h}$. The solution thereafter filtered and the filtrate was evaporated in an oven at $38^{\circ} \mathrm{C}$. The yield of the extract was $10 \% \mathrm{~W} / \mathrm{W}$ with reference to powdered leaves.

Experimental groups: Randomly, 56 male SpragueDawley rats weighing 250-300 g were divided to seven different groups ( 8 heads per group). Untreated control group, vehicle treated that received distilled water by gavage that considered as sham group, aqueous and methanolic extracts treated rats received AP by gavage $\left(100,200,300\right.$ and $\left.400 \mathrm{mg} \mathrm{kg}^{-1}\right)$. Hypertensive treated rats that received Ephedrine and the most effective dose of AP extracts and hypertensive controlled rats received distilled water.
Experimental protocol: Rats were housed in an air conditioned animal house at $23 \pm 2^{\circ} \mathrm{C}$ on a light/dark cycle and supplied with free access to standard pellet diet and tap water. The animals received human care in compliance. Before experimental protocol, rats were allowed to accommodate the laboratory environment for $1 \mathrm{~h}$ and base-line BP was measured using a tail-cuff (NIBP controller) connected to computerized registering device. Results were registered every $5 \mathrm{~min}$ for $40 \mathrm{~min}$. The BP and HR were also recorded $40 \mathrm{~min}$ following oral administration of aqueous and methanolic extracts (300, 400, $\left.500 \mathrm{mg} \mathrm{kg}^{-1}\right)$. Control rats $(n=8)$ received distilled water by the same way. A single dose of ephedrine $\left(40 \mathrm{mg} \mathrm{kg}^{-1}\right.$, intramuscular) was used to raise the blood pressure by 20-30 $\mathrm{mmHg}(\mathrm{n}=8)$ and were regarded as hypertensive rats. Then the effect of the most effective dose of aqueous and methanolic extracts on systolic and diastolic BP and the HR were recorded. This protocol was approved by the Ethic Committee of the Physiology Research Center of Kerman, Iran, which is in accordance with the internationally accepted principles for laboratory animal use and care as found in the European Community guidelines (EEC Directive of $1986 ; 86 / 609 / \mathrm{EEC}$ ) or the US guidelines (NIH publication \#85-23, revised in 1985).

Data analysis: The data were presented as mean \pm SEM of 8 rats in each group. Student pair T-test was used to compare the mean differences between two groups and ANOVA test (post hoc bonferroni) to compare the mean of effects among different groups. $P$ values of less than 0.05 were considered as statistical significance.

\section{RESULTS}

The effect of AP extracts on BP and HR of normotensive rats: Neither methanolic nor aqueous extracts of AP could change the diastolic BP and HR of rats, while doses of 300,400 and $500 \mathrm{mg} \mathrm{kg}^{-1}$ significantly decreased systolic blood pressure compared with the control group $(\mathrm{p}<0.05)$. After 20 min post drug administration the mean systolic blood pressure detected by concentrations of 300, 400 and $500 \mathrm{mg} \mathrm{kg}{ }^{-1}$ of aqueous extract were 125.21 \pm 6.25 , $117.00 \pm 3.71$ and $130.86 \pm 2.19 \mathrm{mmHg}$ respectively, compared to the control group $(138.74 \pm 4.05)(\mathrm{p}<0.05)$. Following methanolic AP extract administration, the mean systolic blood pressure for the concentrations of 300,400 and $500 \mathrm{mg} \mathrm{kg}^{-1}$ were 127.81 \pm 6.08 , 
$110.00 \pm 5.46$ and $127.17 \pm 4.42 \mathrm{mmHg}$ respectively. The highest antihypertensive activity of both aqueous and methanolic AP extracts was with a dose of $400 \mathrm{mg} \mathrm{kg}^{-1}$, 20 min post drug administration (138.74 44.05) as shown in Fig. 1 and $2(\mathrm{p}<0.05)$.

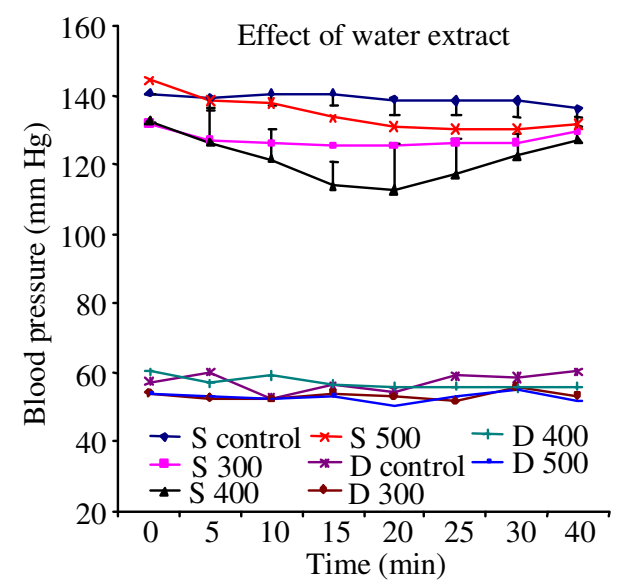

Fig. 1: Effect of different concentrations of water extract of AP on systolic and diastolic blood pressure of normotensive rats compared to control group. Aqueous extract (300, 400 and $500 \mathrm{mg} \mathrm{kg}^{-1}$ ) of AP was administered orally to treated rat groups, systolic and diastolic blood pressure was measured for $40 \mathrm{~min}$. Control rats received distilled water. Data are recorded as mean \pm SEM of 8 rats in each group. $\mathrm{D}=$ Diastolic blood pressure, $\mathrm{S}=$ Systolic blood pressure and $\mathrm{AP}=$ Artemisia Persia

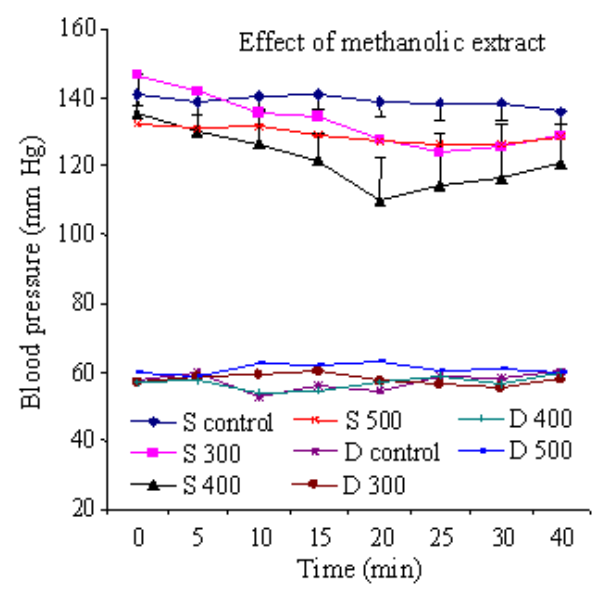

Fig. 2: The effect of different concentrations of methanolic extract of AP on systolic and diastolic BP of normotensive rats compared to control group $(\mathrm{N}=8)$. Methanolic extract of AP was administered (300, 400 and $500 \mathrm{mg} \mathrm{kg}^{-1}$ ) orally to treated rat groups and systolic and diastolic blood pressure was measured for 40 min. Control rats received distilled water. Data are recorded as mean $\pm S E M$ of 8 rats in each group. $\mathrm{D}=$ Diastolic blood pressure, $\mathrm{S}=$ Systolic blood pressure and AP = Artemisia Persia

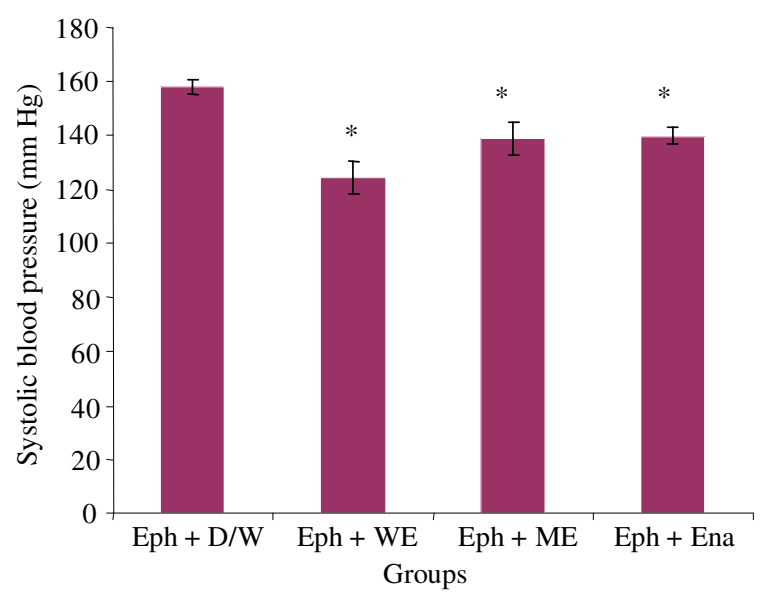

Fig. 3: The most effective dose of aqueous and methanolic extracts of AP $\left(400 \mathrm{mg} \mathrm{kg}^{-1}\right)$ on systolic blood pressure of hypertensive rats. Ephedrine (40 mg kg $\mathrm{mg}^{-1}$ ) caused a 20$30 \mathrm{mmHg}$ elevation in systolic BP in treated rats. The most effective dose of aqueous and methanolic extracts of AP (400 mg kg-1) was given to treated rats and systolic blood pressure was measured before and every 5 min after AP administration. Data are the mean \pm SEM of 8 rats in each group. Aqueous extract reduced the BP significantly $(\mathrm{p}<0.05)$ but the methanolic extract lowered the BP almost in similar way as enalapril in hypertensive rats compared with control group $(*=\mathrm{p}<0.05)$. WE $=$ Water Extract, $\quad \mathrm{EE}=$ Methanolic Extract, Eph $=$ Ephedrine and Ena $=$ Enalapril

The effect of AP extracts on BP and HR of hypertensive rats: Ephedrine $\left(40 \mathrm{mg} \mathrm{kg}^{-1} \mathrm{IM}^{-1}\right)$ caused a 20-30 mmHg elevation of systolic blood pressure. The most effective dose of both aqueous and methanolic extract (400 $\mathrm{mg} \mathrm{kg}^{-1}$ ) significantly reduced systolic blood pressure of ephedrine-induced hypertensive rats, compared to control $(\mathrm{p}<0.05)$. The effect of methanolic extract lowered BP almost in a similar manner as enalapril, while the effect of aqueous extract was more predominant as shown in Fig. 3. 
However neither aqueous nor methanolic extracts had significant effect on diastolic blood pressure and HR of hypertensive rats.

\section{DISCUSSION}

The results of this study showed that both aqueous and methanolic extracts of AP produced a significant transitional decrease in systolic BP after 20 min of postadministration, both in normotensive as well as hypertensive rats $(\mathrm{p}<0.05)$. In addition, the antihypertensive effect of methanolic extract was comparable to Enalapril (30 $\mathrm{mg} \mathrm{kg}^{-1}$ ), whiles the effect of aqueous extract at the same dose was more predominant. The effect of aqueous and methanolic extracts of AP on BP is in complete agreements with some of previous reports ${ }^{[1,5,9]}$. The mechanism by which AP decreases the systolic BP in normotensive and hypertensive rats is not determined yet and requires further investigation to elucidate the underlying mechanism(s). Our results showed the oral administration of AP extracts could decrease systolic BP 20 min after consumption while Male SpragueDawley rats weighing 250-300 g were used in this study. this antihypertensive effect are transitional and will returned to pretreatment baseline after 30 or 40 min. Hence those patients using AP for its anthelmintic or antifungal activities should be cautious and consider the transitional effect of AP on their systolic BP, especially the hypotensive patients. On the other hand, the HR was not changed following AP extracts administration, which is not in complete agreement with reports ${ }^{[6,7]}$, thus it is proposed the antihypertensive effect of AP extracts may be mediated by its inhibitory effect on myocardial contractility and vascular dilatory action of Artemisia ${ }^{[5,6,9]}$.

\section{CONCLUSION}

In summary the results of this study showed both aqueous and methanolic extracts of AP produced a significant transitional decrease in systolic $\mathrm{BP}$, but not in the diastolic BP and HR of normotensive as well as hypertensive rats. Despite the fact that further investigation is necessary to elucidate the underlying mechanism(s), the patients who use AP for its anthelmintic or antifungal activities should be cautious and consider the transitional effect of AP on their systolic BP, especially the hypotensive patients.

\section{ACKNOWLEDGEMENT}

This study was carried out in Physiology Research Center of Kerman University of Medical Sciences. The funding of this study was provided by research deputy of Kerman University of Medical Sciences, Kerman, Iran (85/99).

\section{REFERENCES}

1. Bilia, A.R., D. Lazari, L. Messori, V. Taglioli, C. Temperini and F.F. Vincieri, 2002. Simple and rapid physico-chemical methods to examine action of antimalarial drugs with hemin: Its application to Artemisia annua constituents. Life Sci, 70:769-778. PMID: 11833740.

2. Dell'Eva, R., U. Pfeffer, R. Vene, L. Anfosso, A. Forlani, A. Albini and T. Efferth, 2004. Inhibition of angiogenesis in vivo and growth of Kaposi's sarcoma xenograft tumors by the anti-malarial artesunate. Biochem. Pharmacol., 68: 23592366. PMID: 15548382.

3. Chen, H.H., H.J. Zhou and X. Fang, 2003. Inhibition of human cancer cell line growth and human umbilical vein endothelial cell angiogenesis by artemisinin derivatives in vitro. Pharmacol. Res., 48: 231-236. PMID: 12860439.

4. Lee, S.H., M.Y. Lee, H.M. Kang, D.C. Han, K.H. Son, D.C. Yang, N.D. Sung, C.W. Lee, H.M. Kim and B.M. Kwon, 2003. Anti-tumor activity of the farnesyl-protein transferase inhibitors arteminolides, isolated from Artemisa. Bioorgan. Med. Chem., 11: 4545-4549. PMID: 14527550.

5. Kim, D.H., H.K. Na, T.Y. Oh, W.B. Kim and Y.J. Surh, 2004. Eupatilin, a pharmacologically active flavone derived from Artemisia plants, induces cell cycle arrest in ras-transformed human mammary epithelial cells. Biochem. Pharmacol., 68: 10811087. PMID: 15313404.

6. Yamahara, J., G. Kobayashi, H. Matsuda, T. Katayama and H. Fujimura, 1989. The effect of scoparone, a coumarin derivative isolated from the Chinese crude drug Artemisiae capillaris flos, on the heart. Chem. Pharmacol. Bull., 37: 1297-1299. PMID: 2630096. 
7. Yamahara, J.K.G., 1989. Vascular dilatory action of Artemisia capillaris bud extracts and their active constituent. J. Ethnopharmacol., 26: 129-136. PMID: 2601354.

8. Anfosso, L., T. Efferth, A. Albini and U. Pfeffer, 2006. Microarray expression profiles of angiogenesis-related genes predict tumor cell response to artemisinins. Pharmacogenom. J., 6: 269-278. PMID: 16432535.

9. Zhou, H.J., W.Q. Wang, G.D. Wu, J. Lee and A. Li, 2007. Artesunate inhibits angiogenesis and downregulates vascular endothelial growth factor expression in chronic myeloid leukemia K562 cells. Vasc. Pharmacol., 47: 131-138. PMID: 17581794.
10. Calderone, V., E. Martinotti, B. Baragatti, M.C. Breschi and I. Morelli, 1999. Vascular effects of aqueous crude extracts of Artemisia verlotorum Lamotte (Compositae): In vivo and in vitro pharmacological studies in rats. Phytother. Res., 13: 645-648. PMID: 10594931.

11. Tigno, X.T. and E. Gumila, 2000. In vivo microvascular actions of Artemisia vulgaris $\mathrm{L}$. in a model of ischemia-reperfusion injury in the rat intestinal mesentery. Clin. Hemorheol. Microcircul., 23: 159-165. PMID: 11321436.

12. Tigno, X.T., F. de Guzman and A.M. Flora, 2000. Phytochemical analysis and hemodynamic actions of Artemisia vulgaris L. Clin. Hemorheol. Microcircul., 23: 167-175. PMID: 11321437. 